\title{
The Analysis of Outdoor Climate, Moist Air Enthalpy and their Relation to Cooling Energy Consumption in the Tropics
}

\author{
Waraporn Rattanongphisat $^{1 *}$, Anantachai Suwannakom ${ }^{2}$ \\ ${ }^{I}$ Energy Technologies Building Laboratory, Department of Physics, Faculty of Science, \\ Naresuan University, Phitsanulok, Thailand \\ ${ }^{2}$ Department of Physics, Faculty of Science, Naresuan University, Phitsanulok, Thailand \\ *Corresponding author E-mail: warapornr@nu.ac.th
}

\begin{abstract}
The air conditioned auditorium classroom was monitored for energy consumption by a monitoring platform. One year collected data from energy consumption and indoor climate monitoring systems and outdoor climate data in Phitsanulok province, Thailand, where its climate classified as the tropics, was employed to determine their relation by regression analysis. The analysis of climate data showed that the outdoor temperature above $26{ }^{\circ} \mathrm{C}$ was accounted for $70 \%$ of the year this emphasizes on cooling requirement. Furthermore, the hourly cooling energy consumption ranged from 8.1 to $10.3 \mathrm{kWh}$ for indoor air temperature between $20{ }^{\circ} \mathrm{C}$ and $32{ }^{\circ} \mathrm{C}$. The higher outdoor temperature causes the greater cooling energy consumption. The correlation between outdoor temperature and cooling energy consumption with linear regression showed the correlation coefficient of 0.38 while the correlation between temperature difference and enthalpy difference of the outdoor and indoor found the correlation coefficient of 0.71 . This pointed out that the outdoor tropical climate highly affected to the cooling energy demand.
\end{abstract}

Keywords: Moist air; Psychrometric; Tropics; Cooling energy; Enthalpy

\section{Introduction}

The rise of global temperature due to climate change has been realised. The statistical data recorded since 1880 show the warmest year in 2016 with the global surface temperature of $0.99{ }^{\circ} \mathrm{C}$ above the average global surface temperature relative to 1951 1980 [1]. Researches show the impact of climate change on the building energy utilization particularly HVAC (heating, ventilation and air conditioning system). The prediction of heating energy demand in cold climate countries would reduce in 2050 according to the increase of global temperature [2]. On the contrary, the cooling energy demand in hot climate countries would be increased [3]. Thailand climate is classified as tropical which indicates for warm to hot and humid. The indoor environmental satisfaction mostly reach under air-conditioned; hence, long operating hours can easily be seen in economically affordable buildings e.g. high income family residence, office and factory. The number of Thai buildings equipped with air conditioning climbed up every year. Not to mention that new buildings have designed to living in air-conditioned. Home towns built for small families that building with less opening for natural air flow has been seen and with little insulation of the building envelope as to reduce the cost. Air conditioners would become necessary for the occupants who live in such buildings. A comfort temperature of the indoor environment is expected. This is considered a significant point relate to cooling energy demand which has caused air conditioning system as a predominant energy consuming appliance in the building. Building energy management involved in monitoring, big data analysis and control strategy has become more attractive to modern life style as well as energy conservation perspective. Smart buildings have been mentioned and practiced more. Smart meters, wireless sensors incorporated with internet connection can be setup the platform for the monitoring system.

Prior research work, the air conditioned auditorium classroom was implemented the monitoring system for energy consumption and indoor environmental parameters [4]. The measured power consumption of air conditioning system, temperature, humidity and time of use were display on the screen in real time as well as transferring the data to collection in the server. The indoor environmental parameters were employed for the thermal comfort analysis which suggested the comfort temperature in this conditioned space. The results show the increase of $2^{\circ} \mathrm{C}$ on the temperature setting combined with thermal inertia would reduce $18 \%$ cooling energy consumption. Others also reported that, by increasing $1^{\circ} \mathrm{C}$ on the thermostat setting, the energy reduction of about $6 \%$ can be found in Singapore and Thailand while the power consumption reduced further to $34.4 \%$ when raising $2^{\circ} \mathrm{C}$ in Taiwan [5]. These are supported well by adaptive thermal comfort model that regarding to adapted behavior of people in the tropics to the outdoor climate thus lesser cooling can be expected. Thermal preference subject to warmth in relevant of indoor and outdoor temperature was presented [6]. They reported that it is not always the optimum for thermal comfort at the considered neutral point on the ASHRAE scale. Since the optimum on the scale varies with the indoor temperature and the predominant outdoor temperature. These realized the influential of outdoor temperature on the indoor optimum temperature. It has been reported that the building energy performance was affected by climate condition due to global climate change in which urban climate of Rome, Italy was studied [7]. The urban climate included air temperature and relative humidity was monitored in four areas neighboring of Rome for three years as to investigate the urban heat island effect. It was found that the cooling consumption increased up to $53 \%$ and $74 \%$ for 
residential and office buildings respectively. It has been seen that the global climate has impacted building energy consumption.

The objective of this research is to investigate the relation between cooling energy consumption of air conditioned space and outdoor climate. The data mining from the energy consumption and indoor climate monitoring system of an air-conditioned lecture hall at Physics Department building, Phitsanulok province, Thailand was employed. The regression analysis was used to find the correlation of those parameters. The correlation between outdoor moist air and cooling energy demand was analyzed, discussed and presented. The research finding on the effect and relation between outdoor climate and cooling energy consumption would be benefit to building energy management in this climate region.

\section{Methodology}

The monitoring systems stored power consumption and indoor environmental data of the air conditioned lecture hall at Physics Department was employed and analysed. More detail of the monitoring system of this air conditioned space can be seen in the previous publication [4]. Measured data were recorded in every minute $24 / 7$ in 2015 which were downloaded from the server via the internet connection. Cooling energy consumption was calculated from the measured power. The recorded indoor temperature and relative humidity data were analysed the same period of the outdoor temperature and relative humidity data for the relation between them. In the analysis, the outdoor weather data in 2015 was supported by Thai Meteorological Department, Phitsanulok, Thailand. Enthalpy of moist air, the combination of dry air and water vapour, was calculated from the relative humidity and temperature data by using Psychrometric equation [8]. Then, the correlation of enthalpy difference between outdoor and indoor moist air and temperature difference of the two, cooling energy consumption, outdoor environmental parameters and other related were analysed by using regression analysis.

\subsection{Psychrometric equations}

The moist air enthalpy is a composition of dry air and saturated vapor that can be determined as follows:

$\mathrm{h}=\mathrm{h}_{\mathrm{a}}+\mathrm{Wh} \mathrm{h}_{\mathrm{g}}$

where

$\mathrm{h}$ is moist air specific enthalpy, $\mathrm{kJ} / \mathrm{kg}$

$h_{a}$ is specific enthalpy for dry air, $\mathrm{kJ} / \mathrm{kg}$

$\mathrm{h}_{\mathrm{g}}$ is specific enthalpy for saturated water vapour, $\mathrm{kJ} / \mathrm{kg}$

Replace the function of dry air enthalpy and saturated water vapour enthalpy into equation (1) thus the moist air enthalpy become

$h=1.006 . t+W(2501+1.86 t)$

The humidity ratio is a function of partial pressure and barometric pressure of atmospheric air as

$\mathrm{W}=0.621945 \mathrm{p}_{\mathrm{w}} /\left(\mathrm{p}-\mathrm{p}_{\mathrm{w}}\right)$

where $\mathrm{p}=$ barometric pressure of atmospheric air, $\mathrm{Pa}$

$\mathrm{p}_{\mathrm{w}}=$ partial pressure of water vapour, $\mathrm{Pa}$

The relative humidity is the ratio of the partial pressure of water vapour to the water vapour saturation pressure. Hence, the partial pressure of water vapour can be expressed as

$\mathrm{p}_{\mathrm{w}}=\mathrm{RH} \cdot \mathrm{p}_{\mathrm{ws}}$

where $\mathrm{RH}=$ relative humidity, \%

$\mathrm{p}_{\mathrm{ws}}=$ water vapour saturation pressure, $\mathrm{Pa}$
The water vapour saturation pressure $\left(\mathrm{p}_{\mathrm{ws}}\right)$ is a function of absolute temperature as

$\ln \mathrm{p}_{\mathrm{ws}}=\mathrm{C} 8 / \mathrm{T}+\mathrm{C} 9+\mathrm{C} 10 \mathrm{~T}+\mathrm{C} 11 \mathrm{~T} 2+\mathrm{C} 12 \mathrm{~T} 3+\mathrm{C} 13 \ln \mathrm{T}$

where $\mathrm{T}$ is air temperature, $\mathrm{K}$

$\mathrm{C} 8=-5.8002206 \times 10^{3}, \mathrm{C} 9=1.3914993$,

$\mathrm{C} 10=-4.8640239 \times 10^{-2}, \mathrm{C} 11=4.1764768 \times 10^{-5}$

$\mathrm{C} 12=-1.4452093 \times 10^{-8}, \mathrm{C} 13=6.5459673$

Substitute equation 3, 4, 5 into 2 then the moist air enthalpy became

$\mathrm{h}=1.006 . \mathrm{t}+\frac{0.621945\left(\mathrm{RH} \cdot \mathrm{p}_{\mathrm{ws}}\right)(2501+1.86 \mathrm{t})}{\left(\mathrm{p}-\mathrm{p}_{\mathrm{ws}}\right)}$

where $\mathrm{t}$ is air temperature, ${ }^{\circ} \mathrm{C}$

The enthalpy difference between outdoor and indoor moist air is indicated the moist air sensible cooling

$\mathrm{q} / \dot{\mathrm{m}}=\mathrm{h}_{\text {outdoor }^{-}} \mathrm{h}_{\text {indoor }}$

The cooling and dehumidification of moist air has involved the condensation of moisture of the cooled moist air when its temperature is lower than dew point temperature. The cooling requirement for the steady flow process is

$\mathrm{q} / \dot{\mathrm{m}}=\left[\left(\mathrm{h}_{\text {indoor }}-\mathrm{h}_{\text {outdoor }}\right)-\left(\mathrm{W}_{\text {indoor }}-\mathrm{W}_{\text {outdoor }}\right) \mathrm{h}_{\mathrm{w} \text {,indoor }}\right]$

\subsection{Monitoring Data of Air Conditioned Classroom}

Power consumption was recorded every minute 24/7 when the air conditioner has switched off it written in the time slot as naught. Calculation for cooling energy consumption from the recorded power consumption is written

$\mathrm{E}_{\text {cooling }}=$ Recorded Power $\mathrm{x}$ Time period

The correlation between the cooling energy consumption and other weather data included outdoor and indoor of temperature and relative humidity could be done by plotting the graph of parameter one against parameter two and employing linear regression.

\section{Data Involvement}

To analyse large data of both outdoor and indoor climate in relevant to the energy consumption of air conditioned space, it could take time but the benefit is the understanding of whole picture to future building energy conservation. In the current study, the climate data included temperature, relative humidity and calculated moist air enthalpy were rearranged, sorted and evaluated in the base of time period with the cooling consumption data from the air condition classroom.

\section{Results and Discussion}

Plotted the outdoor temperature against the outdoor relative humidity illustrates where the large number of samples is as shown in Fig.1. The majority of outdoor climate data was with high humidity where the relative humidity of over $60 \%$ was detected at the temperature from $25{ }^{\circ} \mathrm{C}$ to $30{ }^{\circ} \mathrm{C}$. Thermostat temperature setting at $25{ }^{\circ} \mathrm{C}$ is recommended by energy conservation scheme in Thailand for air conditioned space. In fact, it has often been observed the occupants behaviour in putting more clothes on 
while stay in such a conditioned environment. Previous study show the calculation of predicted mean vote, thermal comfort index, lower than naught indicated uncomfortably cold for students wearing uniform clothes [4]. Considering people adapted their behaviour to the climate, the air temperature above the recommendation for an air conditioned space can be suggested energy saving by setting thermostat at higher temperature than it used to be in order to reach the adaptive thermal comfort. Alternately, the setting for comfort temperature for Thailand climate was reported for about $24-26{ }^{\circ} \mathrm{C}$ [5]. In the current analysis, it showed people possibly feeling uncomfortably warm most of the time in the year which accounted for $75 \%$ or 274 days out of 365 days referring to the outdoor temperature above $26^{\circ} \mathrm{C}$. If temperature of $25^{\circ} \mathrm{C}$ was considered, uncomfortable condition would be increased to 292 days accounted for $80 \%$ of the time of the year. Warm and humid climate throughout the year is observed.

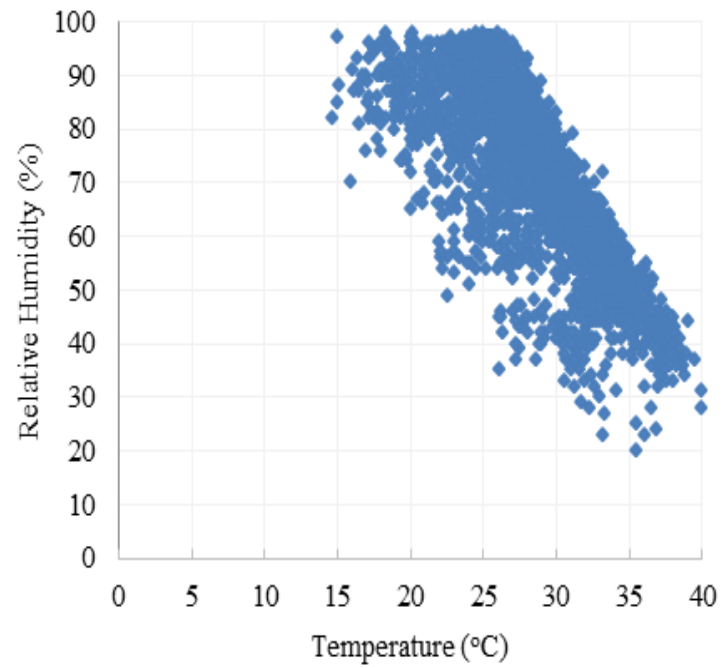

Fig. 1: Hourly outdoor temperature versus hourly outdoor relative humidity in 2015

The maximum and minimum outdoor temperature with their humidity for each month are shown in Table 1 . The lowest humidity was observed in April as well as the maximum outdoor temperature as shown in Table 2 . The relative humidity line in comfortable zone referred to the range of $40 \%$ and $60 \%$. The percentage of outdoor climate at Phitsanulok province provide the picture on the majority of the time that humidity is over $60 \%$ for $75 \%$ of the time of the year. Considering the outdoor climate where the temperature above $26^{\circ} \mathrm{C}$ with high relative humidity i.e. over $60 \%$ cause uncomfortably humid, this would be accounted for $73 \%$ as shown in Table 2. The air conditioner not only provided low air temperature but also adjusted air humidity at the evaporator. Air with high humidity, need to be cooled down, pass through cooling coil. Once the cool air temperature reached its dew point the condensation occurs which resulted in lower outlet air humidity.

Table 1: Maximum and minimum outdoor temperature and humidity

\begin{tabular}{|c|c|c|c|c|}
\hline \multirow{2}{*}{ Month } & \multicolumn{4}{|c|}{ Outdoor climate } \\
\cline { 2 - 5 } & Tmax, ${ }^{\circ} \mathrm{C}$ & $\begin{array}{c}\mathrm{RH} \\
\text { (of Tmax), \% }\end{array}$ & Tmin, ${ }^{\circ} \mathrm{C}$ & $\begin{array}{c}\mathrm{RH} \\
\text { (of Tmin), \% }\end{array}$ \\
\hline Jan & 34.1 & 31 & 14.7 & 82 \\
Feb & 35.9 & 38 & 17.7 & 78 \\
Mar & 36.9 & 24 & 22.3 & 95 \\
Apr & 40 & 28 & 20 & 72 \\
May & 39 & 44 & 24.6 & 92 \\
Jun & 39.5 & 37 & 24.6 & 95 \\
Jul & 37.8 & 36 & 23.8 & 96 \\
Aug & 36 & 49 & 23.6 & 95 \\
Sep & 34.5 & 54 & 24.5 & 96 \\
Oct & 34.5 & 50 & 21.2 & 96 \\
Nov & 35.3 & 49 & 21.8 & 88 \\
Dec & 34.8 & 43 & 18.8 & 92 \\
\hline
\end{tabular}

Table 2: Annual percentage of outdoor temperature and relative humidity

\begin{tabular}{|c|c|l|l|r|}
\hline Toutdoor $\left({ }^{\circ} \mathrm{C}\right)$ & $\%$ & & RHoutdoor $(\%)$ & $\%$ \\
\hline $14.7 \square \mathrm{T}<24.6$ & 15 & & $28 \square \mathrm{RH}<40$ & 3 \\
\hline $24.6 \square \mathrm{T}<26$ & 12 & & $40 \square \mathrm{RH}<60$ & 22 \\
\hline $26 \square \mathrm{T}<34.1$ & 63 & & $60 \square \mathrm{RH}<80$ & 35 \\
\hline $\mathrm{T} \square 34.1$ & 10 & & $80 \square \mathrm{RH}<100$ & 40 \\
\hline Total & 100 & & Total & 100 \\
\hline
\end{tabular}

The average hourly cooling energy consumption is found that the highest consumption is during the period where the air conditioned space is having indoor air temperature between $20{ }^{\circ} \mathrm{C}$ and less than $24{ }^{\circ} \mathrm{C}$ as illustrated in Table 3. It should be noted that only the hourly cooling energy consumption during steady operation were used in the analysis. Outdoor and indoor climate conditions of this one year observation shown in Fig.2.

Table 3: Percentage of indoor temperature and hourly energy consumption of an air conditioned room

\begin{tabular}{|c|c|c|}
\hline Tindoor $\left({ }^{\circ} \mathrm{C}\right)$ & $\%$ & $\begin{array}{c}\text { Average hourly energy con- } \\
\text { sumption }(\mathrm{kWh})\end{array}$ \\
\hline $20 \square \mathrm{T}<24.6$ & 64 & 10.3 \\
\hline $24.6<\mathrm{T}<26$ & 3 & 9.5 \\
\hline $26<\mathrm{T} \square 32$ & 32 & 8.1 \\
\hline Total & 100 & - \\
\hline
\end{tabular}

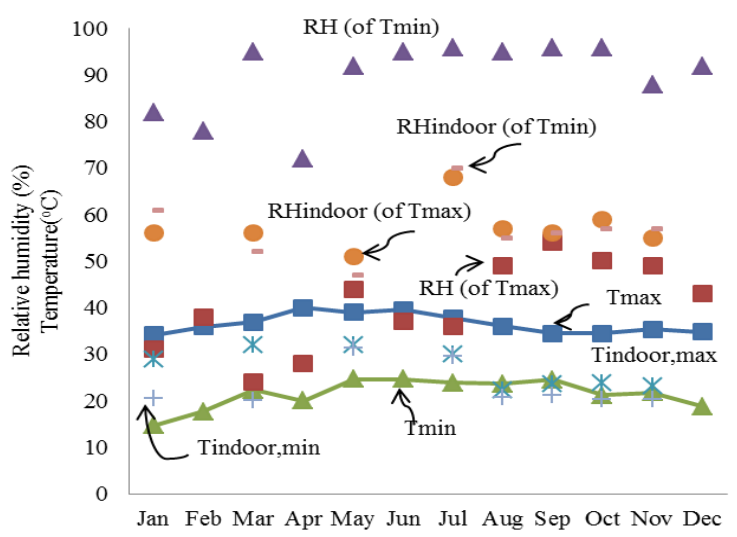

Fig. 2: Range of maximum and minimum of outdoor and indoor temperature and relative humidity of air conditioned space

The correlation between cooling energy consumption and outdoor temperature is shown in Fig.3. The simple linear regression perform with the correation coefficient of 0.39 . Although the coefficient is quite low, the trend of relation between the two clearly has been seen that the increase of outdoor temperature relavant to an increase of cooling energy consumption. Unfortunately, less energy data were collected during the summer months, April and May, according to the failure part of the air conditioner caused long time maintainance. One year data was analysed as to provide the whole picture without considering the variation of the season climate.

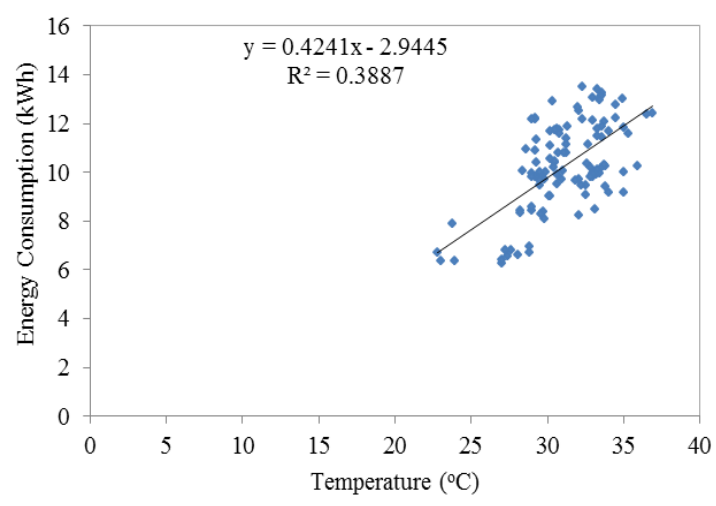

Fig. 3: The correlation between the outdoor temperature and hourly cooling energy consumption 


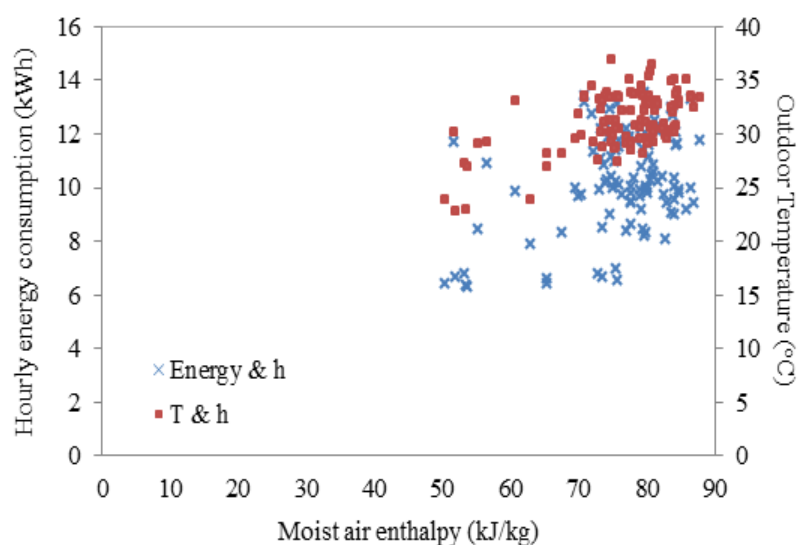

Fig. 4: The relation of outdoor temperature, moist air enthalpy and hourly cooling energy consumption.

It can be seen the variation in moist air enthalpy to the hourly energy consumption shown in Fig.4. Hardly find the correlation of energy consumption to the moist air enthalpy but it can be seen the trend of change in the way the higher moist air enthalpy, the combine property of outdoor moist air temperature and relative humidity, is the higher the energy consumption with regard to the increase of outdoor temperature.

The variation of outdoor moist air data relates with the change of energy consumption. The rise of outdoor temperature causes the increase of energy consumption. The outdoor temperature has affected more on the cooling energy consumption than relative humidity. It should be noted that the highest and the lowest value of energy consumption has been neglected due to the situation when air conditioner not operate properly because of failure parts and running only fan coil unit at low power consumption. In such a case the indoor temperature would hardly meet the occupant comfort. For the same outdoor temperature but various relative humidity values this has found that higher relative humidity trend to increase cooling energy consumption more by about $0.5 \%$ for each per cent increased.

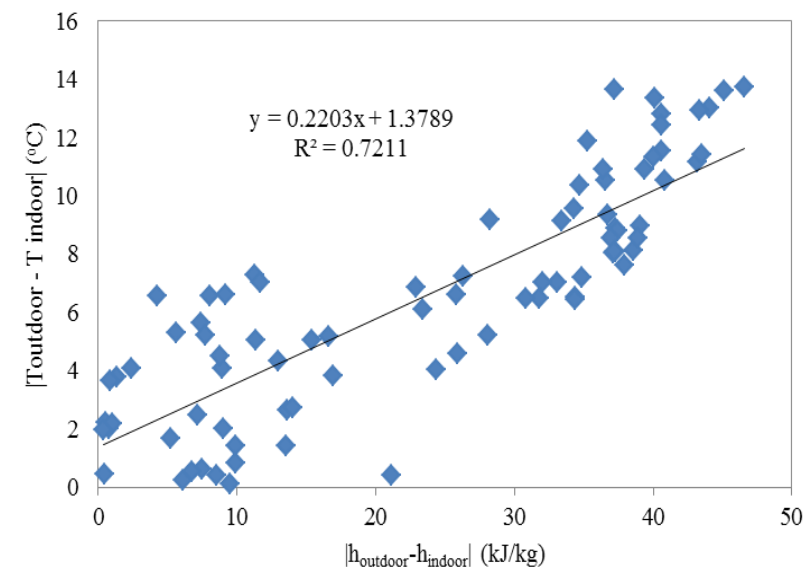

Fig. 5: The correlation between the absolute enthalpy difference and temperature difference of the moist air outdoor and indoor of air-conditioned space

The correlation between temperature difference and enthalpy difference in which the difference between the outdoor and indoor conditions perform found the correlation coefficient of 0.71 as shown in Fig.5. This indicates the effect of outdoor climate on the cooling energy demand.

It has been seen that cooling energy consumption does not correlate with indoor cold air temperature alone but involve with air humidity. Further work shall be done as to provide clearer picture of this part.

\section{Conclusion}

Outdoor weather data has been employed to find the relation between climate condition and the cooling energy consumption under tropical climate. This research carried out in the city of Phitsanulok, Thailand where the recorded power consumption was downloaded from the monitoring platform and be used in the analysis. It has been found that the outdoor temperature play an important role on the cooling demand while high relative humidity could increase the cooling demand further at the same outdoor temperature by $0.5 \%$ for each per cent of humidity increased.

\section{Acknowledgement}

This research project was financial supported by Naresuan University.

\section{References}

[1] https://climate.nasa.gov/vital-signs/global-temperature/

[2] Invidiata A, Ghisi E (2016) Impact of climate change on heating and cooling energy demand in houses in Brazil. Energy and Buildings 130, 20-32.

[3] Wan K, Li D, Pan W, Lam J (2012) Impact of climate change on building energy use in different climate zones and mitigation and adaptation implications. Applied Energy 97, 274-282.

[4] Rattanongphisat W, Prachaona T, Harfield A, Sato K, Hanaoka O (2017) Indoor climate data analysis based a monitoring platform for thermal comfort evaluation and energy conservation. Energy Procedia 138, 211-216.

[5] Kwong QJ, Adam NM, Sahari BB (2014) Thermal comfort assessment and potential for energy efficiency enhancement in modern tropical buildings: A review. Energy and Buildings 68, 547-557.

[6] de Dear RJ, Brager GS (2002) Thermal comfort in naturally ventilated buildings: revisions to ASHRAE Standard 55. Energy and Buildings 34, 549-561

[7] Zinzi M, Carnielo E, Mattonia B (2018) On the relation between urban climate and energy performance of buildings. A three-years experience in Rome, Italy. Applied Energy 221, 148-160.

[8] ASHRAE, 2009 ASHRAE Handbook-Fundamentals (SI Edition). American Society of Heating, Refrigerating and Air-Conditioning Engineers Inc, (2009), Atlanta, GA. 